\title{
THE DEVELOPMENT OF AN IDENTIFICATION KEY AND TEST FOR A SALMONID IDENTIFICATION COURSE IN ALBERTA
}
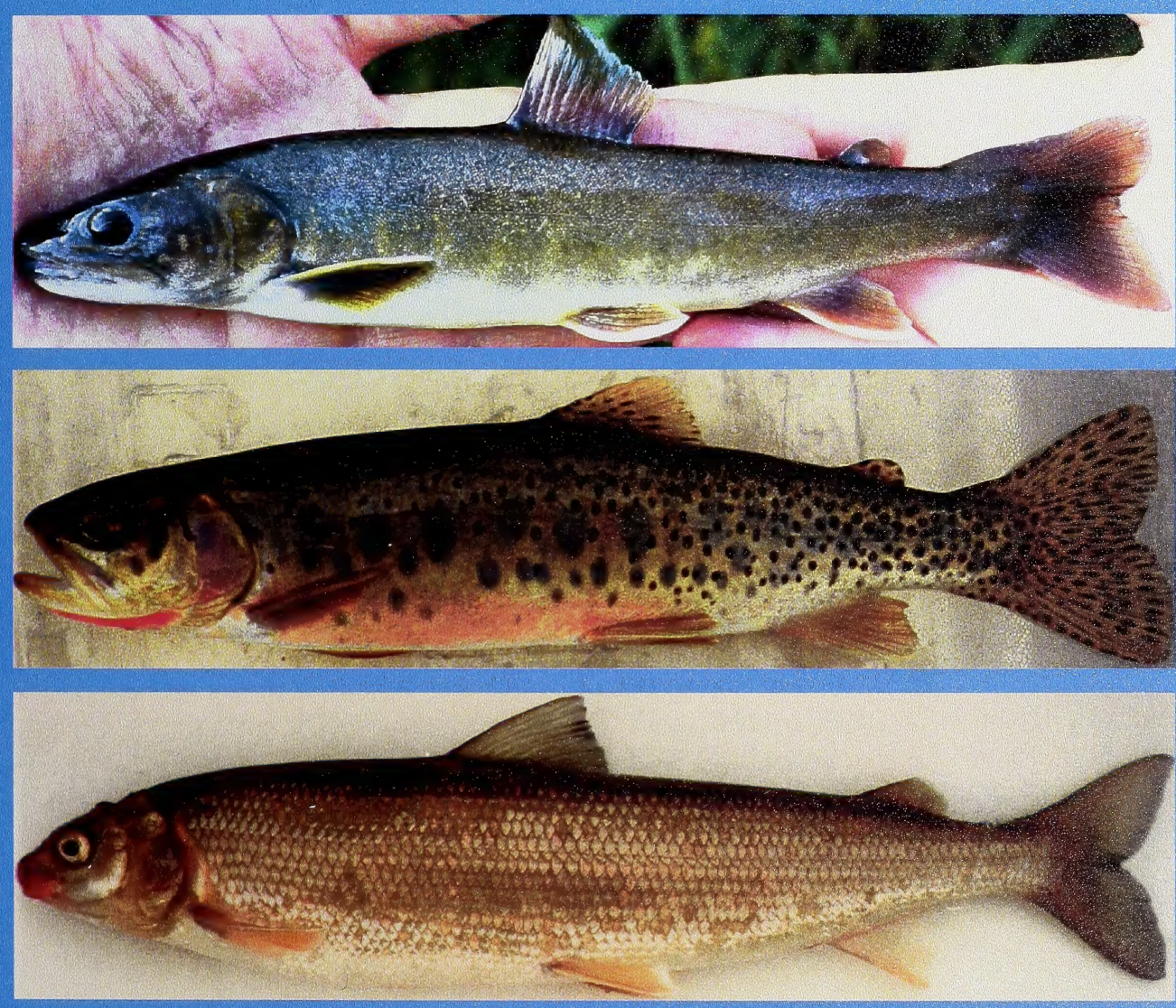
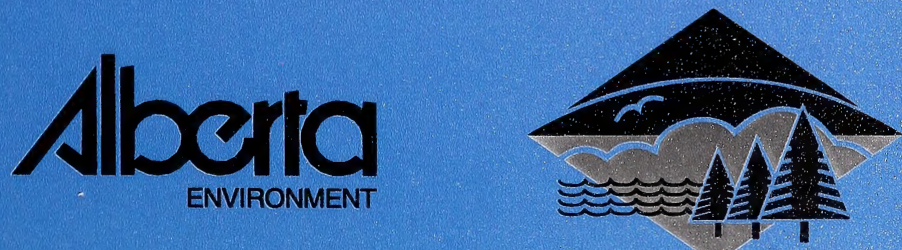

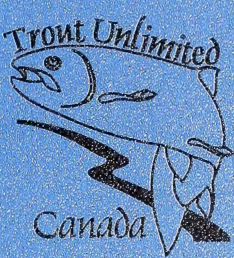




\title{
The Development of an Identification Key and Test for a Salmonid Identification Course in Alberta
}

\author{
By \\ Jim D. Stelfox \\ Alberta Environment, \#100, 3115-12 St. N.E. \\ Calgary, Alberta T2E 7J2, Canada \\ email: Jim.Stelfox@gov.ab.ca; Phone: (403) 297-6183; fax: (403) 297-2843 \\ Georgina E. Shumaker \\ \#105, 10009 Prairie Road \\ Grande Prairie, Alberta T8V 5P3, Canada \\ Phone: (780) 513-6978 \\ Dean M. Baayens \\ Trout Unlimited Canada, P.O. Box 6270, Station D \\ Calgary, Alberta T2P 2C8, Canada \\ email: dbaayens@tucanada.org; Phone: (403) 221-8373; fax: (403) 221-8368 \\ David K. Berry \\ Alberta Environment, $2^{\text {nd }}$ Floor, 9920-108 St. \\ Edmonton, Alberta T5K 2M4, Canada \\ email: Dave.Berry@gov.ab.ca; Phone: (780) 427-8347; fax: (780) 422-9559
}

November 2000

Alberta Environment

Natural Resources Service

Fisheries and Wildlife Management Division 
Pub. No.: $\mathrm{T} / 590$

ISBN: 0-7785-1478-1

Date: November 2000

Reproduction of this document or its contents, in whole or in part, is not granted without permission of the authors. Further information on this document can be obtained by contacting the senior author or the Provincial Recreational Fisheries Specialist ${ }^{1}$.

The suggested appropriate citation for this document is:

Stelfox J.D., G.E. Shumaker, D.M. Baayens, and D.K. Berry. 2000. The development of an identification key and test for a salmonid identification course in Alberta. Alberta Environment. Fisheries and Wildlife Management Division.

Cover Photos:

Top--Bull Trout (Jim Stelfox)

Middle--Cutthroat Trout (Jim Stelfox)

Bottom--Mountain Whitefish (Dean Baayens)

1 -- David K. Berry. Alberta Environment, Fisheries and Wildlife Management Division, South Tower, Main Floor, Petroleum Plaza, 9915-108 St. Edmonton, Alberta, Canada T5K 2G8, (780) 427-8347, Dave.Berry@gov.ab.ca 


\section{PREFACE}

This document outlines the need for better public information and education to assist anglers in the identification of fish to overcome existing problems with misidentification. The pilot testing of material conducted in 1999 and 2000 established a high degree of confidence in the quality of the educational material and instructional methods that have been developed and validated.

The contents of this document are not intended as official material for instruction on salmonid identification. Improvements are planned as outlined in this document and new material is being prepared for inclusion in a companion document "Alberta's Salmonid Identification Course."

The authors gratefully acknowledge the many individuals who assisted with this project. Dave Christiansen and George Sterling (both of Alberta Environment), Wayne Roberts (University of Alberta) and Barry Mitchell (Trout Unlimited Canada) provided initial input into the development of the key and test. Dave Christiansen, Duane Radford (Alberta Environment) and Kerry Brewin (Trout Unlimited Canada) reviewed the manuscript. Several Alberta Environment staff, Alberta Conservation Association staff and Trout Unlimited Canada members submitted photos for consideration, some of which were used in the key and test (and acknowledged adjacent to their photos). Various Alberta Environment staff, Trout Unlimited Canada staff and Gerry Ball (Mount Royal College) helped by administering the test. Many more Alberta Environment staff and family members, some Trout Unlimited Canada members and a few Mount Royal College students participated by taking the test, thus providing the data to evaluate the effectiveness of the key and the suitability of the test photos.

\section{Reep fish in our future!}




\section{TABLE OF CONTENTS}

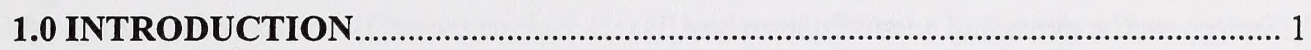

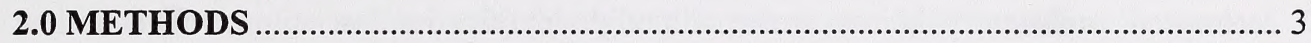

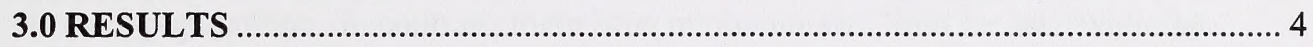

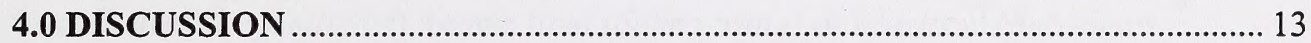

5.0 CONCLUSIONS AND RECOMMENDATIONS............................................ 16

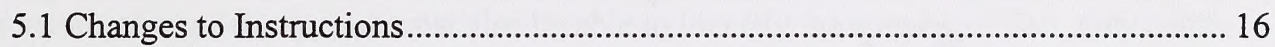

5.2 Changes to Test Answer Sheet ……………………........................................... 16

5.3 Changes to Test Photos...................................................................................... 17

5.4 Changes to the Dichotomous Key and Example Pictures......................................... 17

6.0 REFERENCES

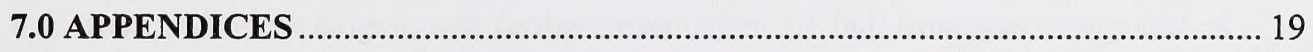

Appendix 1. Salmonid identification test, dichotomous key and example pictures. ... 19 Appendix 2. Objectives and course outline for the salmonid identification course. .... 39 Appendix 3. Test answer sheet for the salmonid identification course. ........................ 43

Appendix 4. Detailed discussion of test results for each photo in the salmonid

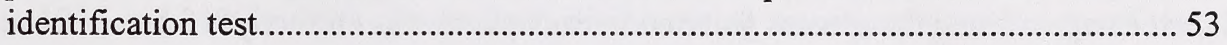




\section{LIST OF FIGURES}

Figure

1. Scores on the salmonid identification test

2. Average second-attempt scores on the salmonid identification test relative to the average first-attempt score within each $25 \%$ category 5

\section{LIST OF TABLES}

Table

1. Average scores relative to number of years fished and trout harvested per year

2. Percentage of time the species featured in each photo was correctly identified $(n=261)$

3. Average percentage of time the photo of a species was correctly identified.

4. Number of times the species was incorrectly identified and percentage composition of the incorrect answers. An "X" denotes the correct answer. 8

5. Number and composition of incorrect answers for each species group. An "X" denotes the correct answer. 


\subsection{INTRODUCTION}

Sportfishing regulations in Alberta have become increasingly complex and speciesspecific in an effort to improve fisheries and to prevent the decline of native species. Anglers are required to identify the species of sport fish they catch, as well as the size, to determine if the fish must be immediately released. A province-wide no-harvest regulation is in effect for bull trout (Salvelinus confluentus). Minimum-size limits now apply to cutthroat trout (Oncorhynchus clarki) and rainbow trout (Oncorhynchus mykiss) in Eastern Slopes streams, and to Arctic grayling (Thymallus arcticus) and mountain whitefish (Prosopium williamsoni) throughout the province. Minimum-size limits also apply to the majority of northern pike (Esox lucius) and walleye (Stizostedion vitreum vitreum) populations. In contrast, there is no minimum-size limit for lake whitefish (Coregonus clupeaformis) and only a few waters have minimum-size limits for brook trout (Salvelinus fontinalis), brown trout (Salmo trutta) or lake trout (Salvelinus namaycush).

Compliance with regulations is essential for regulations to work. Anglers must not only be aware of regulations, but must also be able to identify the species of fish they catch. Fortunately, it appears that most anglers are conscientious and willing to comply with fishing regulations, but as regulations have become more complex, the issue of fish misidentification has become an increasing concern. For example, the province-wide noharvest regulation for bull trout, implemented in 1995, relies heavily upon the ability of anglers to identify bull trout. To assist anglers with identification of bull trout, the "No black, put it back" slogan was conceived in 1992 and widely publicized. The profile of bull trout, and of the slogan, was further raised when the bull trout was designated as Alberta's provincial fish in 1995 . Despite the considerable publicity given to bull trout and the public education efforts provided by enforcement staff, data gathered by enforcement staff on the Highwood and Sheep rivers (Isley 1997, 1999) suggest that there was a growing problem with misidentification of bull trout by anglers. The percentage of anglers (individuals and groups) who were unable to identify bull trout was $16 \%$ in 1995 , $24 \%$ in 1996 and $31 \%$ in 1998 . Particularly disconcerting was the observation that $51 \%$ of the anglers or groups of anglers surveyed on the Sheep River in 1998 were unable to identify bull trout. The implications are significant, since bull trout comprised $36 \%$ of the reported catch in the Sheep River in 1998, compared to 7\% in the Highwood River (Isley 1999).

Angler misidentification of fish has been documented elsewhere. In west-central Montana, $56 \%$ of anglers surveyed were unable to correctly identify bull trout (Schmetterling and Long 1999). In Idaho, $70 \%$ of the anglers surveyed on the Middle Fork Boise River were unable to correctly identify bull trout (Schill and Lamansky 1999). In the same study, Schill and Lamansky also found that $78 \%$ of fly anglers, $94 \%$ of lure anglers and $98 \%$ of bait anglers were unable to correctly identify all five species of trout (brook trout, bull trout, rainbow trout, cutthroat trout and brown trout). 
The implementation of a brook trout suppression project on Quirk Creek in 1998 (Stelfox et al. in pressA.), which utilizes anglers to selectively harvest brook trout, provided further evidence of fish misidentification and also pointed to a solution. To reduce the chance of anglers accidentally harvesting bull trout or cutthroat trout, a fish identification test and a fish identification key were developed (Stelfox et al. in pressB). The test consisted of 17 photos (five brook trout, eight bull trout and four cutthroat trout) of the three species of trout found in Quirk Creek. To participate in the project, anglers had to score $100 \%$ on the test on one of two attempts. Of the 110 people who took the test in 1998 , only $37 \%$ passed on their first attempt, even though most were experienced fly anglers. Of those who failed, $83 \%$ passed it on their second attempt, after being given a list of the key-identifying features for each species. Average scores on the first and second attempt, for people who failed on their first attempt and took a second attempt, were $83 \%$ and $99 \%$ respectively.

Initial results from the Quirk Creek project are also encouraging pertaining to the longterm retention of the key-identifying features by anglers. The failure rate for anglers who took the three-species test in more that one year was $33 \%$ on their initial first attempt, but only $9 \%$ on their first attempt in subsequent years. Furthermore, of the 5267 fish removed by volunteer anglers participating in the project, only seven fish were misidentified (not a brook trout), which equates to an error rate of only $0.1 \%$.

To date, fish identification information has consisted of providing anglers with drawings, pictures or keys in the sportfishing regulations or placing signs at various locations along some waters. One problem with pictures or drawings is that some have been of poor quality, or the descriptions that accompanied them made reference to features that were subjective or showed considerable variability. Keys, while more precise, often use terminology or make reference to features that many anglers find confusing or overwhelming. Better public information and education was required that would assist anglers in the fast and accurate identification of fish.

Based on the initial success of the test and key used for the Quirk Creek project, Alberta Environment selected a similar approach for the development of a key for the identification of the main salmonid species caught by anglers in Alberta. This report presents the results of testing conducted in 1999 and 2000 to evaluate the effectiveness of a salmonid identification key and the suitability of photos used in a salmonid identification test. 


\subsection{METHODS}

In 1999, a salmonid identification education package was developed. This package included a test, a dichotomous key and example pictures (Appendix 1). The test featured 40 photos (three Arctic grayling, seven brook trout, six brown trout, six bull trout, four cutthroat trout, three lake trout, three lake whitefish, two mountain whitefish and six rainbow trout) that were scanned, cropped and then assembled in PowerPoint to fit on five 8.5 -inch $\times 11$-inch sheets. Photos were selected that showed the variability in appearance and colour that can occur between adult male, adult female and juvenile fish of each species. There was no intent to use photos that were difficult or tricky to identify.

The salmonid identification key was laid out in a step-by-step sequence to lead participants through the process of recognizing the key-identifying features used to separate the fish species. The dichotomous key also included pictures that showed only that portion of the fish with the key-identifying feature (e.g., the dorsal fin). Labelled example pictures of the whole fish (one for each species) were provided to assist people who wished to view the entire fish.

Testing followed the procedures outlined in Appendix 2 and was conducted primarily by Alberta Environment fisheries staff. Participants indicated their answers on the table provided (Appendix 3) and were allowed to take as much time as required to complete the course, with most taking a little more than one hour.

The test was given to participants twice before their tests were marked. At the start of the course, participants were asked to complete the test based on personal knowledge and experience before any instruction and without the use of the key. This established individual baselines to enable the evaluation of the quality of the training material and effectiveness of the course as a teaching tool. The key and example pictures were then provided and instruction was given on fish identification. Participants completed the test a second time with the aid of the key to determine the effectiveness of the key and photos. 


\subsection{RESULTS}

Testing was primarily conducted on Alberta Environment staff. In addition, 40 participants (primarily biologists) from the Bull Trout II Conference (held in Canmore, Alberta, in November 1999), and the Great Plains Fisheries Workers Association meeting (held in Lethbridge, Alberta, in January 2000) took the test. Of the 261 people tested, who indicated their profession, 71 were biologists (fisheries or wildlife), 61 enforcement, 39 administrative, and 10 management. The remaining 80 people were Trout Unlimited Canada members, students from Mount Royal College or the spouses, children and acquaintances of Alberta Environment fisheries staff.

Of the 261 people who took the salmonid identification test twice, only $10 \%$ scored $100 \%$ on their first attempt whereas $33 \%$ scored $100 \%$ on their second attempt. Average first- and second-attempt scores for all 261 people were $69 \%$ and $92 \%$, respectively. People who did not score $100 \%$ on their second attempt had average scores of $58 \%$ and $88 \%$ on their first and second attempts, respectively.

In all but a few cases, scores improved on the second attempt (Figure 1). The most dramatic improvement was for people who scored low on their first attempt (Figure 2). People who scored less than $26 \%$ on their first attempt had average first- and secondattempt scores of $15 \%$ and $80 \%$, respectively. In contrast, people who scored more than $75 \%$ on their first attempt had average first- and second-attempt scores of $93 \%$ and $98 \%$, respectively.

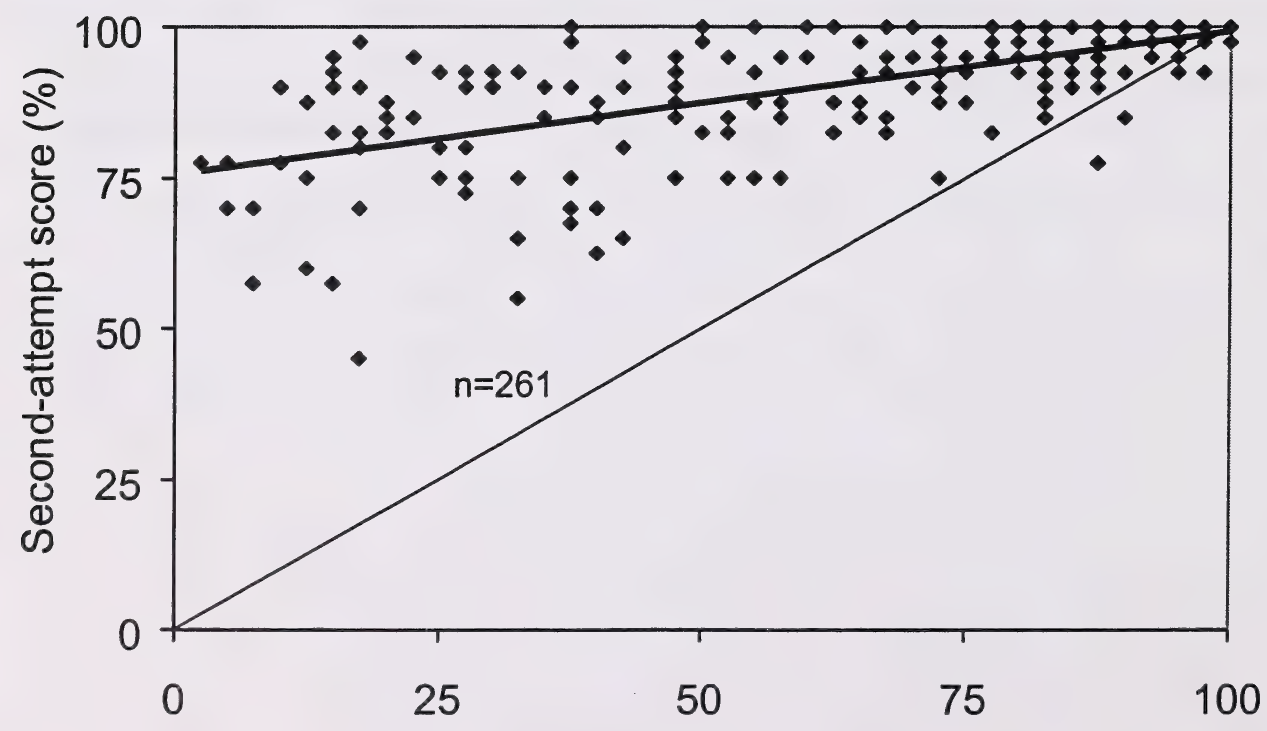

First-attempt score (\%)

Figure 1. Scores on the salmonid identification test. 


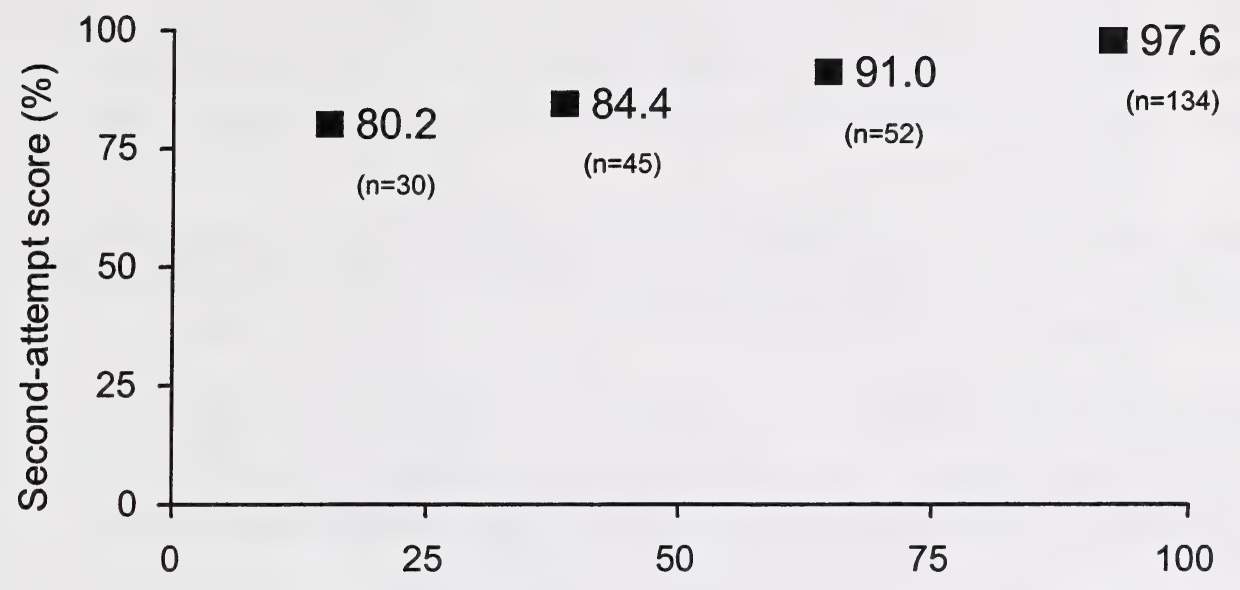

First-attempt score (\%)

Figure 2. Average second-attempt scores on the salmonid identification test relative to the average first-attempt score within each $25 \%$ category.

Table 1. Average scores relative to number of years fished and trout harvested per year.

\begin{tabular}{lccccc}
\hline & & Sample & \multicolumn{2}{c}{ Score (\%) on } \\
\cline { 5 - 6 } & Category & size & First attempt & Second attempt \\
\hline \multirow{2}{*}{ Number of years fished: } & $<1$ & 55 & 38 & 84 \\
& $1-10$ & 43 & 65 & 92 \\
& $>10$ & 154 & 81 & 95 \\
Number of trout harvested/year: & 0 & 131 & 60 & 90 \\
& $1-10$ & 97 & 77 & 95 \\
& $11-20$ & 8 & 86 & 95 \\
& $>20$ & 13 & 89 & 97 \\
\hline
\end{tabular}

Scores were positively correlated to the number of years fished (Table 1), with experienced anglers generally achieving higher first- and second-attempt scores. Nonanglers and people who had fished for less than one year had average scores of $38 \%$ and $84 \%$ on their first and second attempts, respectively. In contrast, people who had fished for more than 10 years had average scores of $81 \%$ and $95 \%$ on their first and second attempts, respectively.

Of the 131 people who indicated that they harvested 0 trout/year, 86 indicated that they fished $<5$ days/year and 43 indicated that they fished $>5$ days/year. Average first- and second-attempt scores were $49 \%$ and $87 \%$ respectively for the first group, but $81 \%$ and $95 \%$ respectively for the second group. Part of the reason for this is that the zero-harvest category contained two distinct groups of people from 
opposite ends of the spectrum -non-anglers and unsuccessful casual anglers who generally fished $<5$ days/year, and ardent (catch-and-release-only) anglers who fished $>5$ days/year. Scores were also positively correlated to the number of trout harvested per year (Table 1), but the relationship was not as pronounced as for the number of years fished.

Although scores improved for all photos on the second attempt, scores for several photos were well below average. In particular, photos 7, 12, 23, 27, 29, 30, 37 and 40 had scores of $86 \%$ or less on the second attempt (Table 2 ).

On the first attempt, participants had more difficulty correctly identifying photos of brown trout, lake trout and bull trout than any of the other species, but the least difficulty with Arctic grayling (Table 3). On the second attempt, participants had more difficulty correctly identifying photos of rainbow trout than any of the other species, but the least difficulty with Arctic grayling and mountain whitefish (Table 3).

A review of the results for each photo for both first- and second-attempt tests (Tables 2, 4 and 5, and Appendix 4) provides insight into what worked, where problems occurred and where improvements can be made in the salmonid identification test and key. Table 4 identifies the species featured in each photo and the number and percentage composition of incorrect answers for each photo. Table 5 provides similar data in a species-grouped summary. Appendix 4 gives a detailed review of the results for each photo, presented in the order that the photo appeared in the test.

Based on an examination of the results for each photo, it is apparent that three of the trout/char species were more frequently confused with a species in another genus on the first attempt than was the case on the second attempt. For example, brown trout were usually misidentified as brook trout on the first attempt and as rainbow trout on the second attempt. Brook trout were more frequently misidentified as brown trout on the first attempt and as lake trout on the second attempt. Lake trout were more frequently misidentified as brown trout on the first attempt and as brook trout on the second attempt.

For the remaining trout/char species, misidentification usually occurred with a species in the same genus. Cutthroat trout were usually misidentified as brown trout on the first attempt and as rainbow trout on the second attempt. Rainbow trout were most frequently misidentified as brown trout on both attempts. Bull trout were most frequently misidentified as lake trout on both attempts. These mistakes are significant, because there is a minimum-size limit for cutthroat and rainbow trout in all Eastern Slopes streams (but none for brown trout in most streams) and a zero bag limit for bull trout.

Mountain whitefish and lake whitefish were most frequently confused with each other on both attempts. This is problematic, because there is currently a minimum-size limit for mountain whitefish but not for lake whitefish.

Arctic grayling photos were seldom misidentified. However, when they were, there was a very slight tendency for them to be misidentified as mountain whitefish. This is problematic, because the current minimum-size limit for mountain whitefish is smaller than for Arctic grayling. 


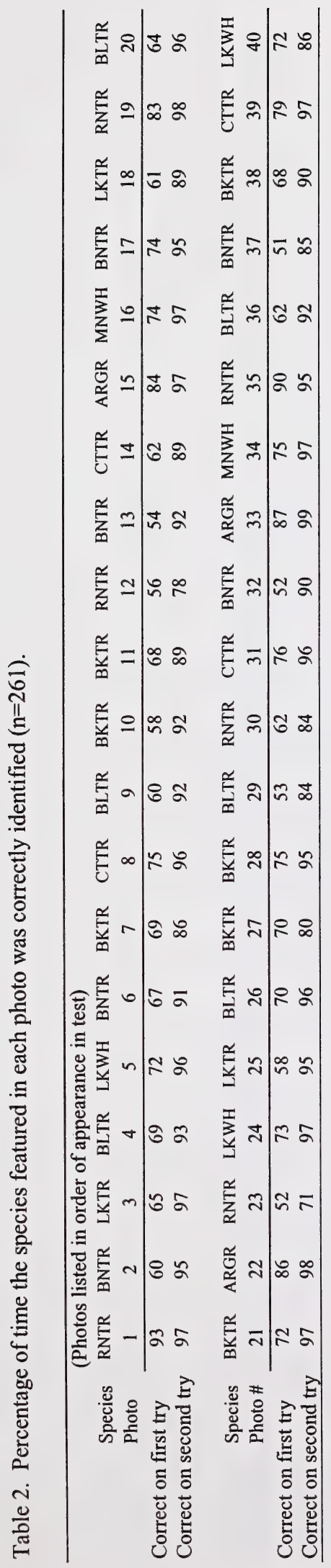

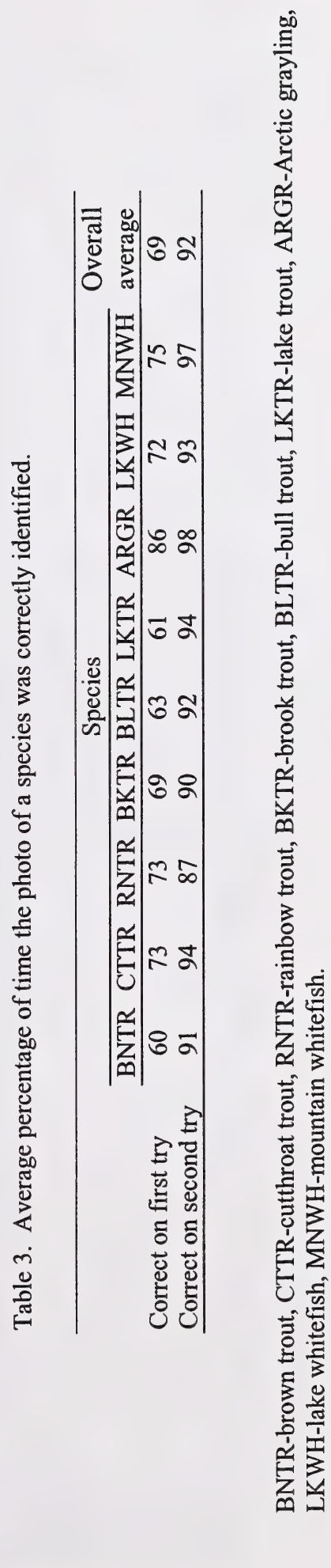




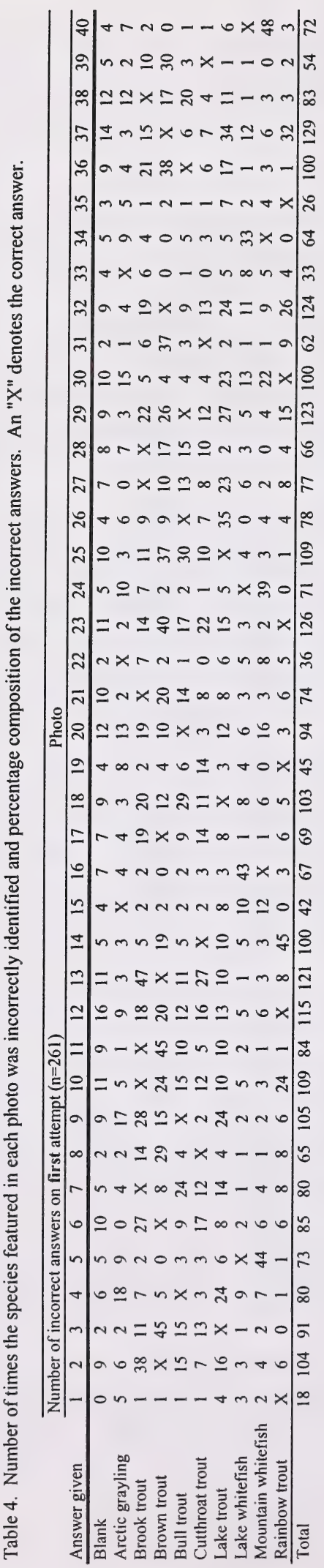

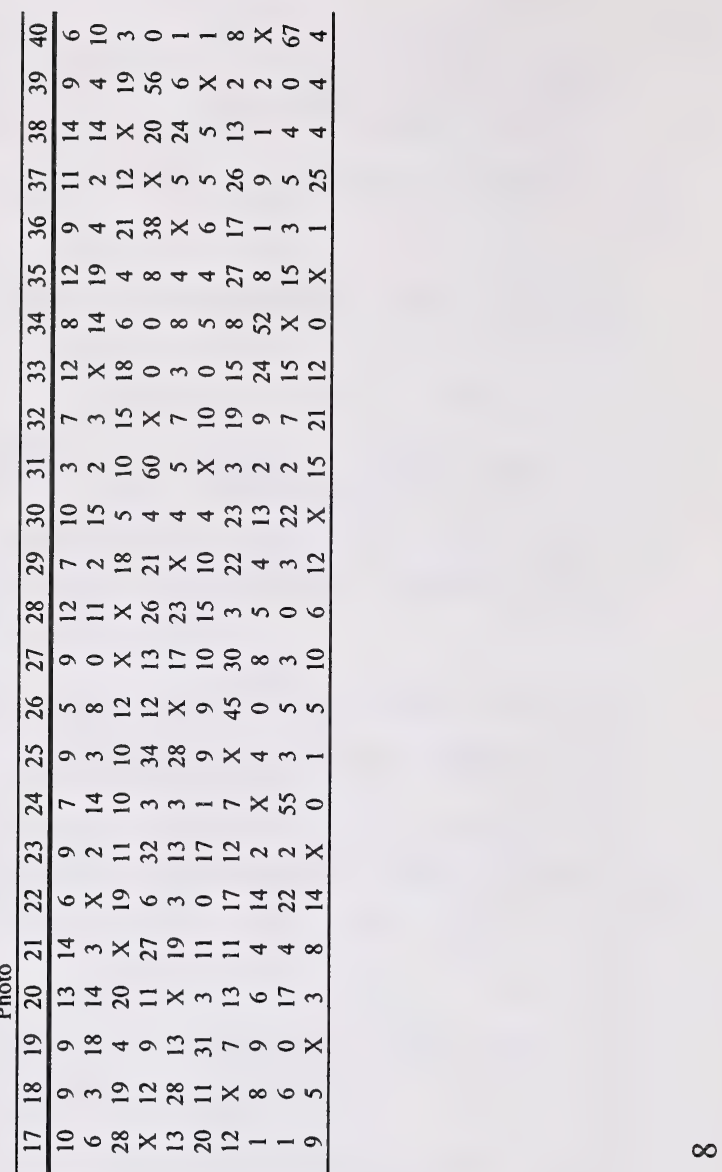

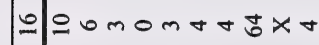

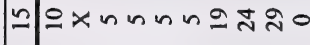
ปnmn $\backsim \backsim \times 0 n m ?$ -

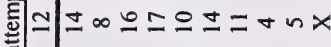
ప్ $=$ = E의으 $x$ ป

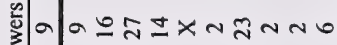
हैmm

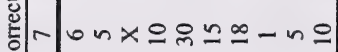
:

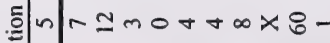
क $+\infty a \cup x+8=a-$

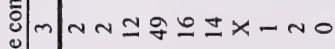

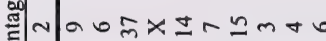
ปั้ 


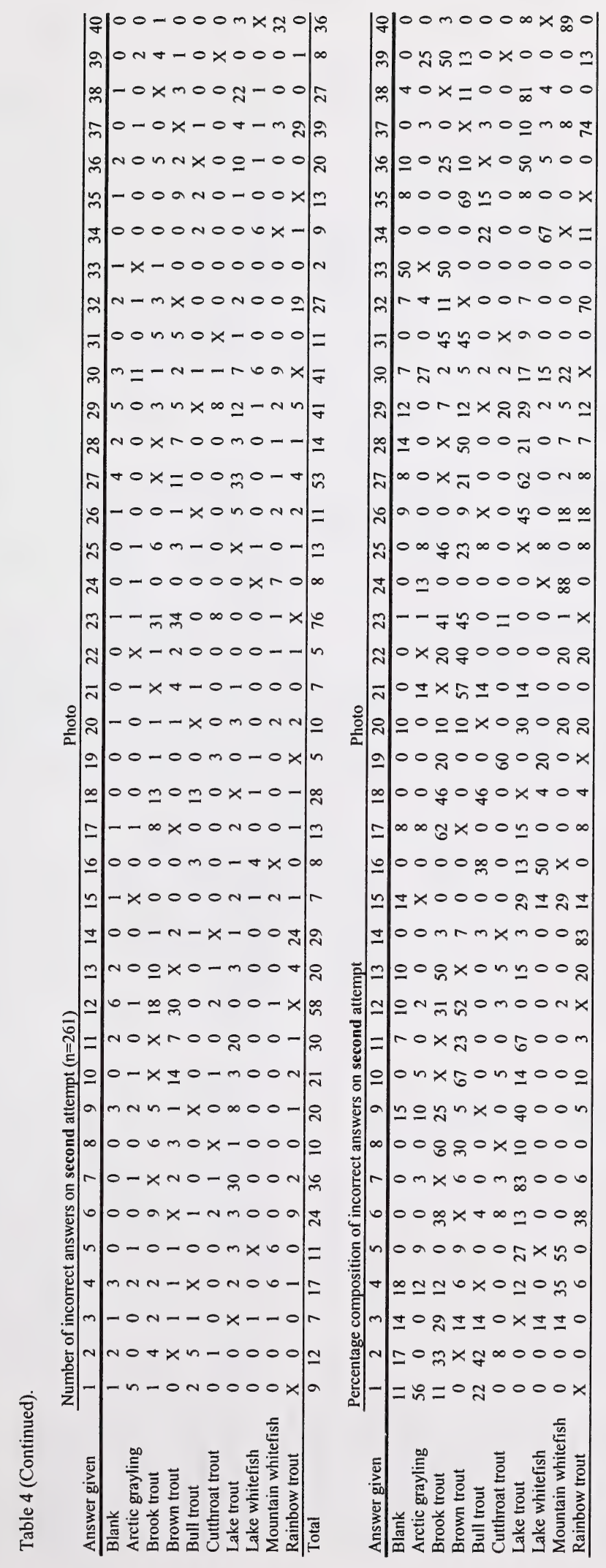




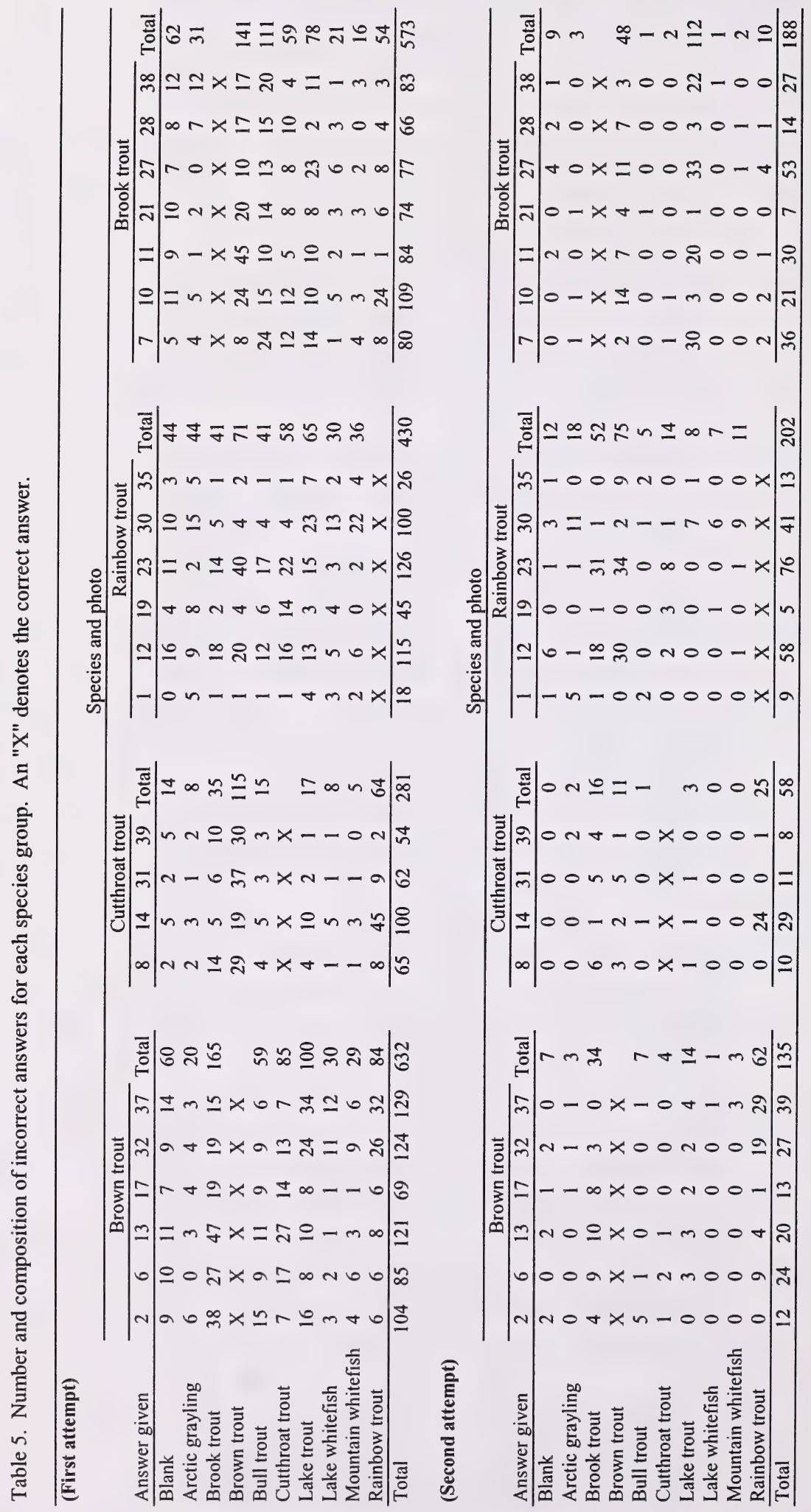




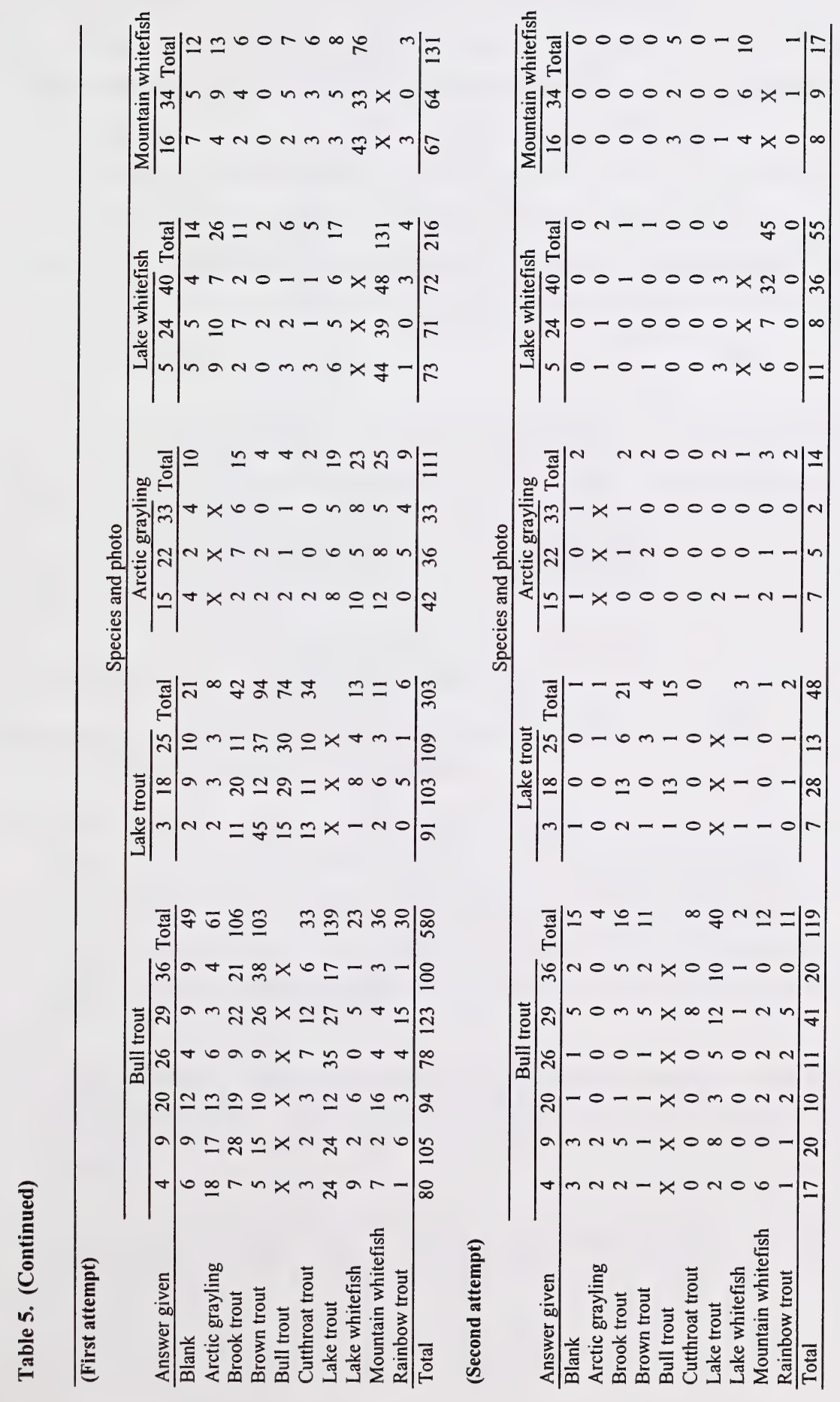


In three cases, there was actually an increase in the number of people misidentifying photos of one species as another species on the second attempt (Table 5). Out of the 261 people tested, 52 misidentified rainbow trout as brook trout on the second attempt compared with 41 on the first attempt. This was primarily due to a doubling of the number of people who called the rainbow trout in photo 23 a brook trout. Similarly, the number of people misidentifying rainbow trout as brown trout increased to 75 on the second attempt from 71 on the first attempt. This was primarily due to an increase in the number of people who misidentified the rainbow trout in photos 12 and 35, as brown trout. Finally, the number of people misidentifying brook trout as lake trout increased to 112 on the second attempt from 78 on the first attempt. This was primarily because of an increase in the number of people misidentifying the brook trout in photos 7, 11, 27 and 38 as lake trout. 


\subsection{DISCUSSION}

The purpose of the testing was to evaluate the effectiveness of the key and the suitability of the test photos-not the fish identification abilities of the participants. Because testing was conducted primarily on Alberta Environment staff (some of whom were anglers and some of whom were not) and most of the participants were biological staff (fisheries or wildlife) or conservation officers, the results may not be indicative of the general angling public.

One technique proved to be especially useful in helping to identify problems with the salmonid identification material. Before marked tests were returned to participants, they were informed of any photos that they misidentified on the second attempt and asked to re-identify the fish in each of those photos. By doing so, it was possible to determine whether an individual was using the key properly and to identify problems with the key and photos. The follow-up review also helped individuals learn how to identify fish by using key-identifying features.

Lack of knowledge was a major factor in misidentification of photos, especially on the first attempt; however, several other factors likely contributed to the misidentification of photos, especially on the second attempt. In some cases, misidentification may be attributed to deficiencies in photo quality, deficiencies in the key, difficulty in identifying juvenile fish, improper usage of the key, problems with the layout of the answer sheet, distractions, or forgetting to mark a row. A brief discussion of these factors is provided below.

\section{Dichotomous Key and Example Pictures}

Data analysis and feedback indicates that there were a number of areas where problems occurred with the key and example pictures.

- Arctic grayling. The secondary-identifying feature-black spots on sides-confused a few people because this same feature is used to differentiate between trout and char. Since the reference to the front of the dorsal fin being rounded is absolute, and more than sufficient to separate grayling from whitefish, dropping the reference to black spots would eliminate the confusion. The description could be further improved by stating: "top of dorsal fin rounded," since this more accurately describes the location of this feature on the dorsal fin.

- Lake whitefish. Many people reported difficulty following the description for lake whitefish in the key. The description of the dorsal fin could be improved and shortened by simply stating: "top of dorsal fin extends beyond back of fin when fin is flattened."

- Cisco. The reference to cisco in the key caused some confusion and caused some people to ask why there were no photos of cisco in the test and no category for cisco 
on the answer sheet. Cisco were included in the original key because they, like lake whitefish, can be readily differentiated from mountain whitefish by examining the dorsal fin. However, since there is currently a combined limit for lake whitefish and cisco, there is no legal need for anglers to be able to tell them apart. Furthermore, since the focus of this test is on the main salmonid species caught by anglers in Alberta, and cisco are seldom caught by anglers, it would be best not to include cisco in the key.

- Brown trout. References to prominent black spots on the gill cover and red spots on the sides caused some confusion. Although brown trout generally have more numerous and more prominent spots on the gill cover than rainbow trout, and red spots are often present on the sides of brown trout, these features are not always evident and are therefore not key-identifying features. Mentioning these secondaryidentifying features tended to detract from the importance of the key-identifying feature-the pale haloes. The above error was quite evident for test photo 35 (a rainbow trout with numerous prominent spots on its gill cover). The description of the key-identifying feature could be improved by reversing the order of the wording to state: "pale haloes around black spots". This change in wording puts more emphasis on the pale haloes that occur on brown trout, but that are absent on rainbow trout.

- Lake trout. The picture of the lake trout dorsal fin in the key needs to be replaced with one that is against a lighter background. The dark background of the current picture makes it appear as though there may be black markings on the dorsal fin, instead of pale spots. Changing the order and wording of the char key would also help to reduce the problem that some people had in identifying char species. It would be better to initially separate out bull trout and then differentiate between brook trout and lake trout, rather than separating out brook trout first. As a result, it would be possible to also reference the deeply forked tail for lake trout, compared with the tail for brook trout (which is not deeply forked), to help people differentiate between brook trout and lake trout.

\section{Difficulty in Identifying Juvenile Fish}

The difficulty in identifying juvenile fish was particularly evident from the low scores that were associated with test photos 12 and 23. Many people misidentified the juvenile rainbow trout in these photos as brown trout because they thought the parr marks were large black spots surrounded by pale haloes. Some of this confusion could be eliminated if, in addition to the current example picture for rainbow trout, an example picture of a rainbow trout with parr marks was provided. Separately labelling parr marks and black spots in the example picture would reduce the potential for the above confusion. As pictures become available, a separate information sheet of the six trout species, featuring example pictures of juveniles with prominent parr marks, could also be added to the instruction material. Since juvenile fish are generally more abundant than adult fish, anglers are probably more likely to catch juvenile fish. Considering that there is a minimum-size limit for rainbow and cutthroat trout in all Eastern Slopes streams, but 
none for brown trout in most streams, it is especially important that anglers are able to identify juveniles.

\section{Improper Usage of the Key}

Improper usage of the key was occasionally a problem and tended to be more of a problem with experienced anglers than with non-anglers and novices. Rather than starting at the top of the key and using the key for each test photo, some experienced anglers prematurely skipped to the bottom of the key or did not use the key when identifying some fish. This was especially evident when trout were misidentified as char and vice versa, which indicated that the person skipped the step regarding the presence or absence of black spots on the sides of the fish.

\section{Problems with the Layout of the Answer Sheet}

The close spacing of the rows on the answer sheet may have resulted in some people checking the wrong row, thus getting two wrong because they had two answers in one row and none in the other. In other instances, the wrong column was checked due to the close proximity of columns for fish with similar names (e.g., lake trout instead of lake whitefish or brook trout instead of brown trout).

\section{Distractions and Carelessness}

Distractions were a problem for a few of the administrative staff. Some of them attempted to do the test between answering the phone, serving the public at the counter and assisting staff. This likely resulted in lower scores for some staff than would have occurred had they completed the test without disruptions.

In other testing situations, some people simply forgot to put a check mark in a row, either because they accidentally skipped a photo or because they intentionally skipped one and meant to come back to it after finishing the rest of the test. On occasion, carelessness may also have contributed to the wrong column being checked.

\section{Test Photo Quality}

Based on feedback from participants and analysis of the data, the quality of a few photos in the test appeared to be problematic. In particular, photos 18, 27 and 37 posed problems because the key-identifying features were not readily discernible due to either the orientation of the fish, surface glare, insufficient lighting of the fish or insufficient contrast between the fish and the background. Replacement of a few test photos would reduce these problems. 


\subsection{CONCLUSIONS AND RECOMMENDATIONS}

The results of this study indicate that problems with salmonid misidentification can be overcome. Although salmonid identification is not always easy for the inexperienced, with training and guidance even the novice can become comfortable with the task. As a result, it is possible for non-anglers and novice anglers using the key to be as proficient at fish identification as experienced anglers are without the key. For example, non-anglers and anglers who had fished for less than one year had average scores of $38 \%$ without the key and $84 \%$ with the key, whereas anglers who had fished more than 10 years had an average score of $81 \%$ without the key.

Although several improvements are planned as outlined below, it is clear that quality instructional material on salmonid identification has been developed and validated by the test results of this study. A high degree of confidence in the quality of the educational material and instructional methods has been established. An individual's difficulty in salmonid identification using the key when taking the test can not be blamed on faulty photos or inappropriate key-identifying features. Appropriate production and distribution of the material as Alberta's Salmonid Identification Course is recommended. The staff of Natural Resources Service can be provided a quality teaching tool to deliver a successful educational program to the public. Undoubtedly, sportfishing organizations and schools will also make use of the salmonid identification material in their own information/education programs.

\subsection{Changes to Instructions}

- When instructions are being given to participants, more emphasis needs to be placed on the importance of using the key for each test photo, and the need to start at the top of the key and follow the sequence each time.

- Participants should be reminded to ensure that they have put a check mark in each row and that there is only one check mark in each row.

- Whenever time permits, and before their tests are returned, participants should be informed of any photos that they misidentified on the second attempt and asked to identify the fish in each of those photos. This will make it possible to determine whether they are using the key properly, to identify problems with the photos or key and to help participants to recognize the key-identifying features.

\subsection{Changes to Test Answer Sheet}

- More space should be provided between the numbered rows, and every fourth row should be shaded instead of every second row, to make it easier for people to find the appropriate row in the table. 
- The order of the columns for fish species should be changed and the species grouped in the same order as presented in the key (i.e., Arctic grayling, whitefish, trout, and char).

\subsection{Changes to Test Photos}

- Test photos 18, 27 and 37 and possibly other photos should be replaced, as better quality photos become available.

\subsection{Changes to the Dichotomous Key and Example Pictures}

- Arctic grayling. The reference to black spots on the sides of Arctic grayling should be dropped, since this is the key-identifying feature used to differentiate between trout and char. The reference to the top of the dorsal fin being rounded is sufficient to separate grayling from whitefish.

- Lake whitefish. The description of the dorsal fin should be improved and shortened by stating, "top of dorsal fin extends beyond back of fin when fin is flattened".

- Cisco. Cisco should be removed from the key.

- Brown trout. The references to prominent spots on the gill cover and red spots on the sides should be dropped, since these are not always evident and are therefore not key-identifying features. The description of the key-identifying feature should be revised by reversing the order of the words to state that there are "pale haloes around black spots", thus putting more emphasis on the pale haloes.

- Lake trout. The picture of the lake trout dorsal fin in the key should be replaced with one that is against a lighter background. The order and wording of the key for char should also be modified, by splitting bull trout off first to reduce the problem that some individuals had differentiating between brook trout and lake trout. In addition, reference should be made to the deeply forked tail for lake trout, compared with the tail for brook trout (which is not deeply forked), to help people differentiate between brook trout and lake trout.

- Rainbow trout. An example picture of a rainbow trout that features parr marks should be added, and the parr marks and black spots should be separately labelled in the picture. This will reduce the potential for people to mistake the parr marks for black spots surrounded by pale haloes. When pictures become available, a separate information sheet of the six trout species, featuring example pictures of juveniles with prominent parr marks, should be prepared. 


\section{REFERENCES}

Isley, Q. 1997. Highwood Drainage Fisheries Report: an overview of the angler survey and enforcement activities on the Highwood drainage, 1994-1996. Natural Resources Service, Alberta Environmental Protection, High River, Alberta.

Isley, Q. 1999. Highwood Drainage Fisheries Review: an overview of violations and angler survey results (1998). Natural Resources Service, Alberta Environmental Protection, High River, Alberta.

Nelson, J.S., and M.J. Paetz. 1992. The fishes of Alberta. 2nd. edition. The University of Alberta Press and The University of Calgary Press. 437 pp.

Schill, D.J. and J.A. Lamansky, Jr. 1999. Angler Behavior Studies: the ability of southwest Idaho anglers to identify five species of trout. Report Number 00-12. Idaho Department of Fish and Game, Boise, Idaho.

Schmetterling, D.A., and M.H. Long. 1999. Montana anglers' inability to identify bull trout and other salmonids. Fisheries 24:7, 24-27.

Stelfox, J.D., D.M. Baayens, A.J. Paul, and G.E. Shumaker. in pressA. Quirk Creek brook trout suppression project. Bull trout II conference proceedings, c/o Trout Unlimited Canada, Calgary, Alberta.

Stelfox, J.D., G.E. Shumaker, and D.M. Baayens. in pressB. Fish identification education. Bull trout II conference proceedings, c/o Trout Unlimited Canada, Calgary, Alberta. 
Appendix 1. Salmonid identification test, dichotomous key and example pictures. 



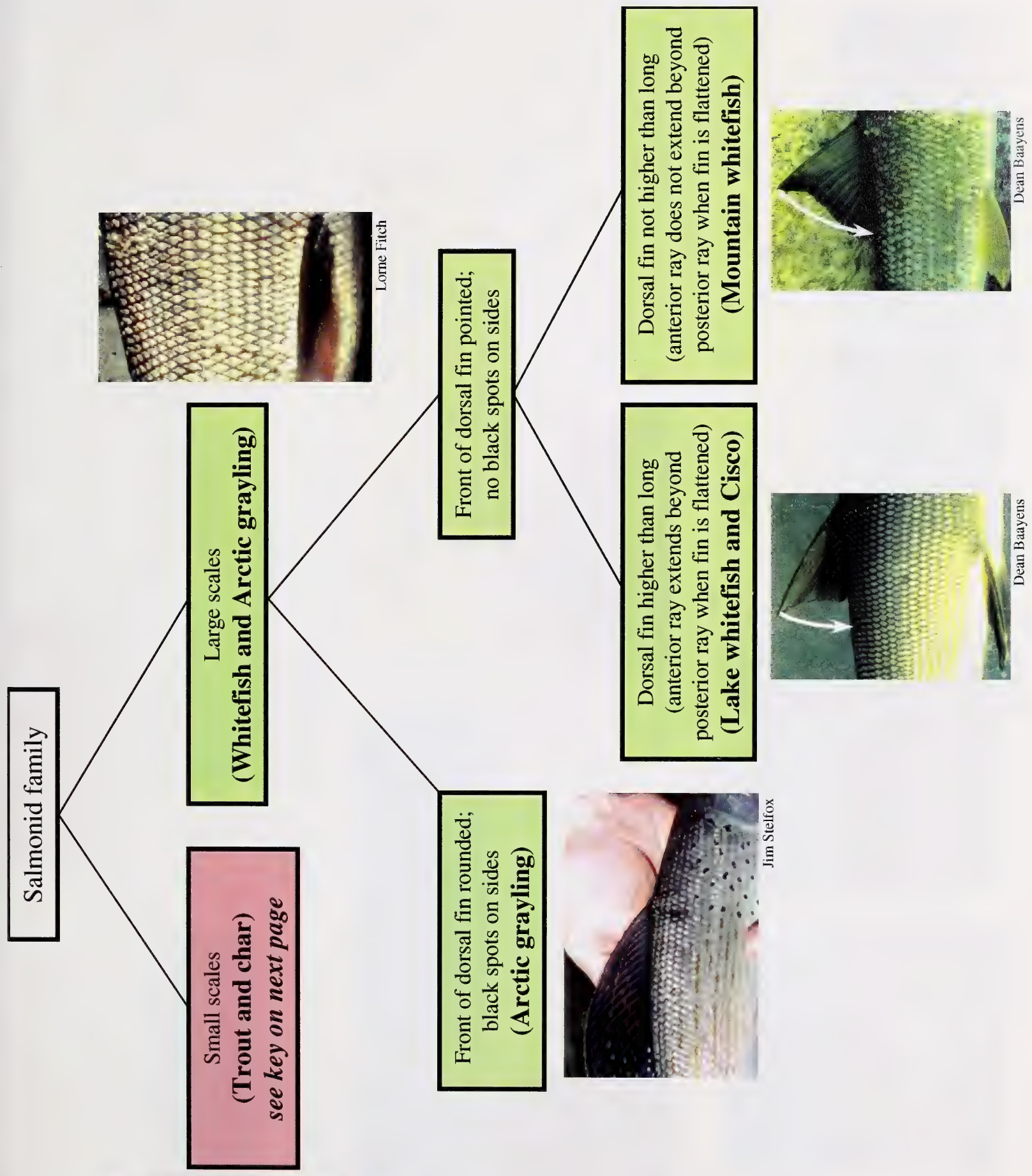




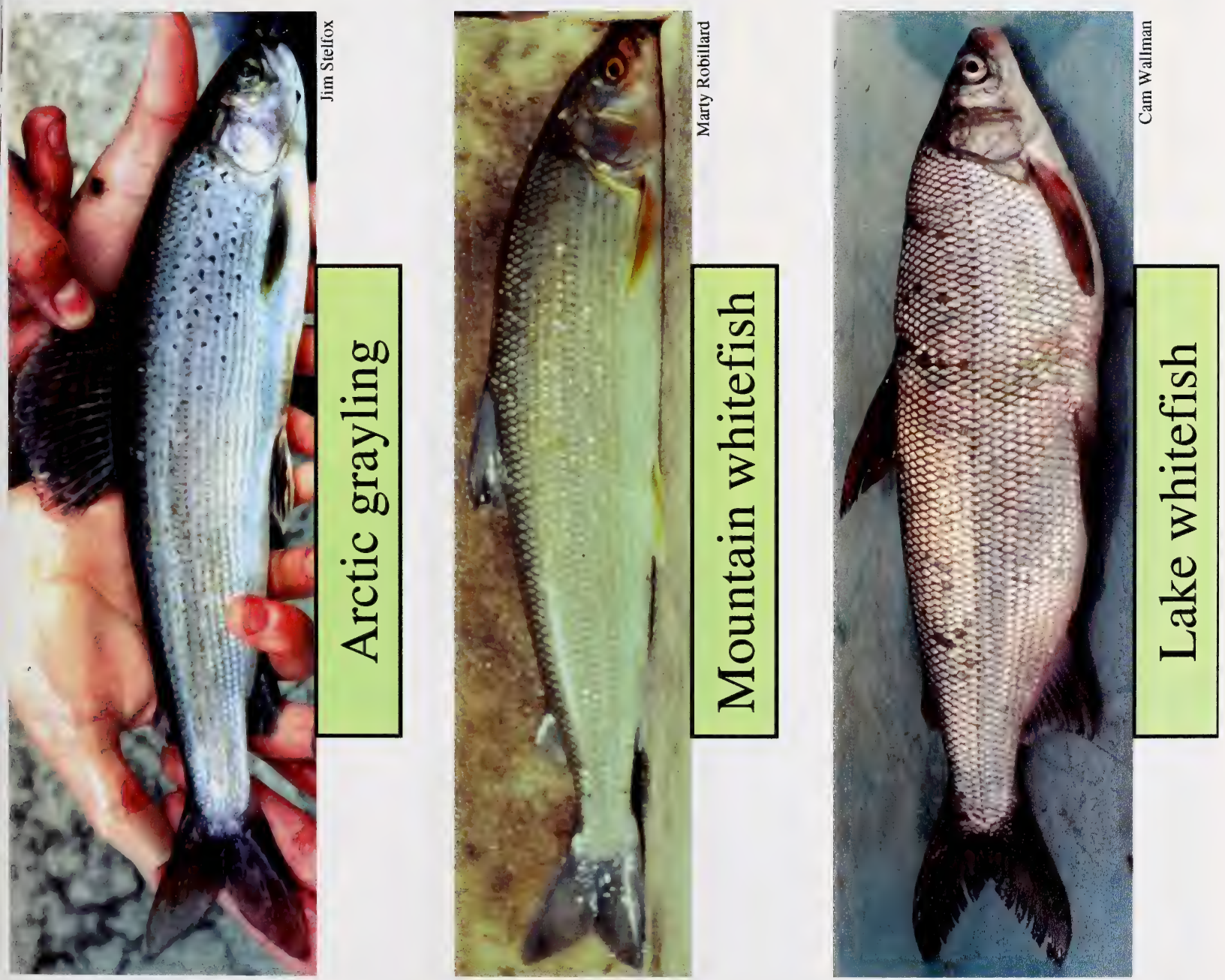


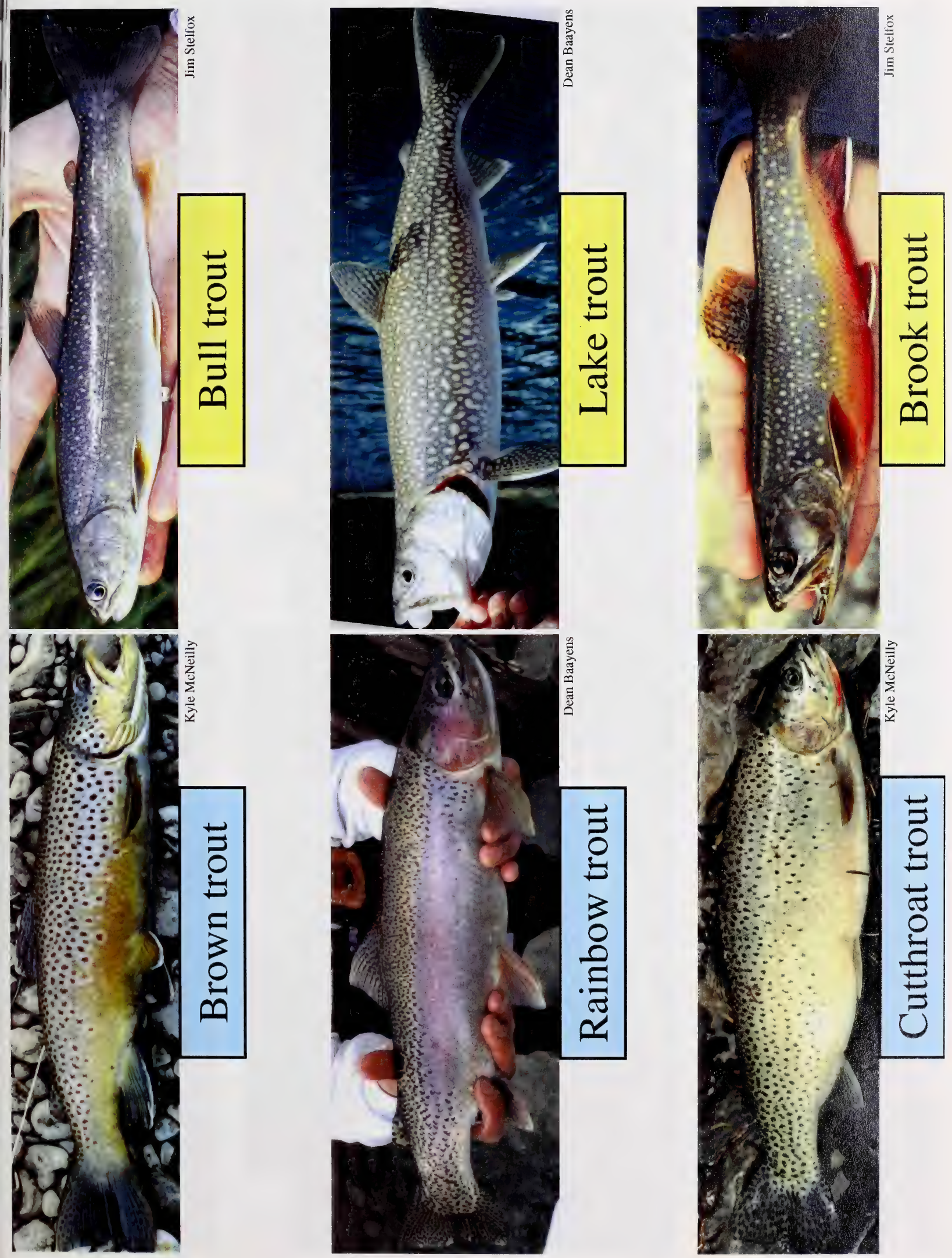

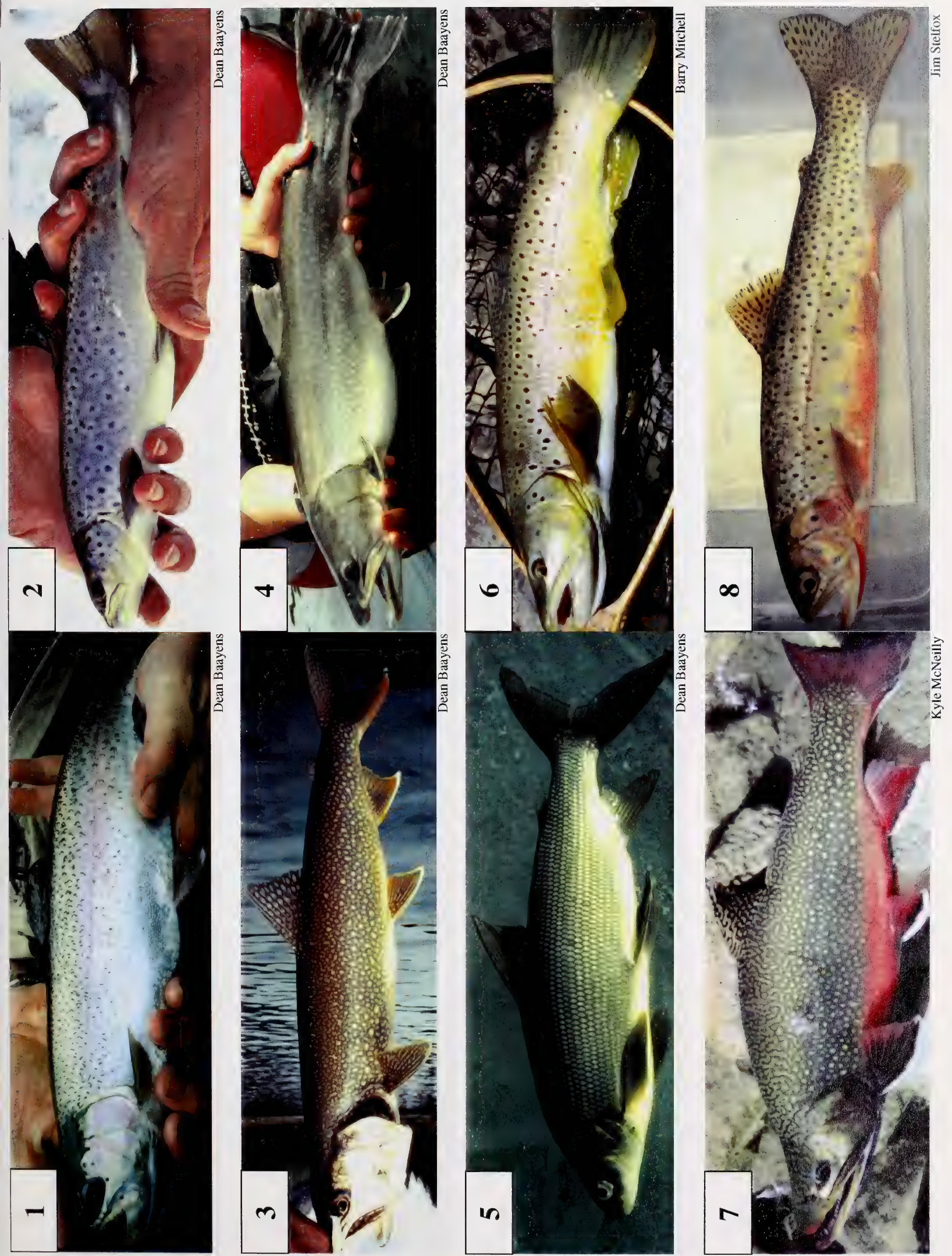


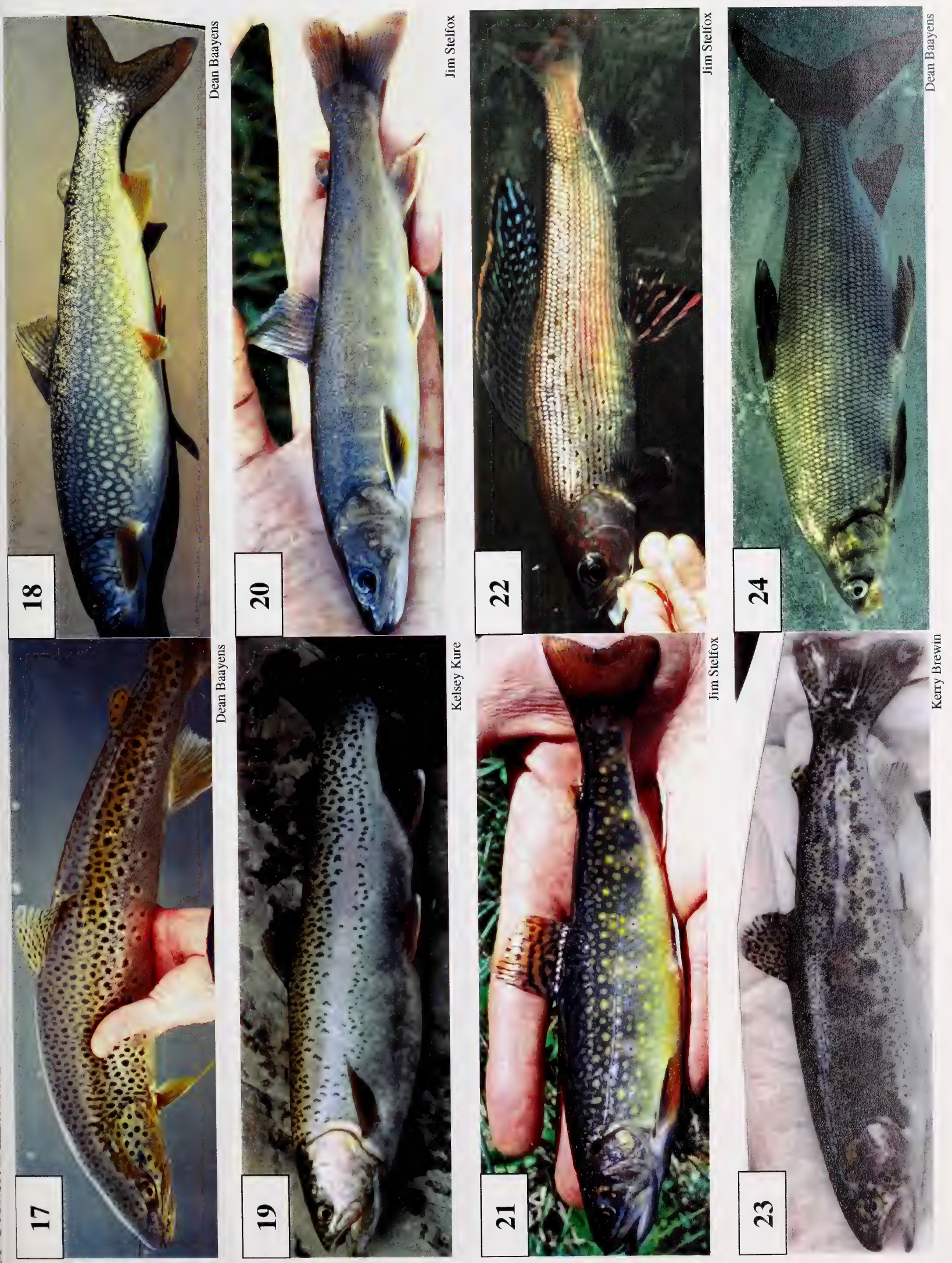




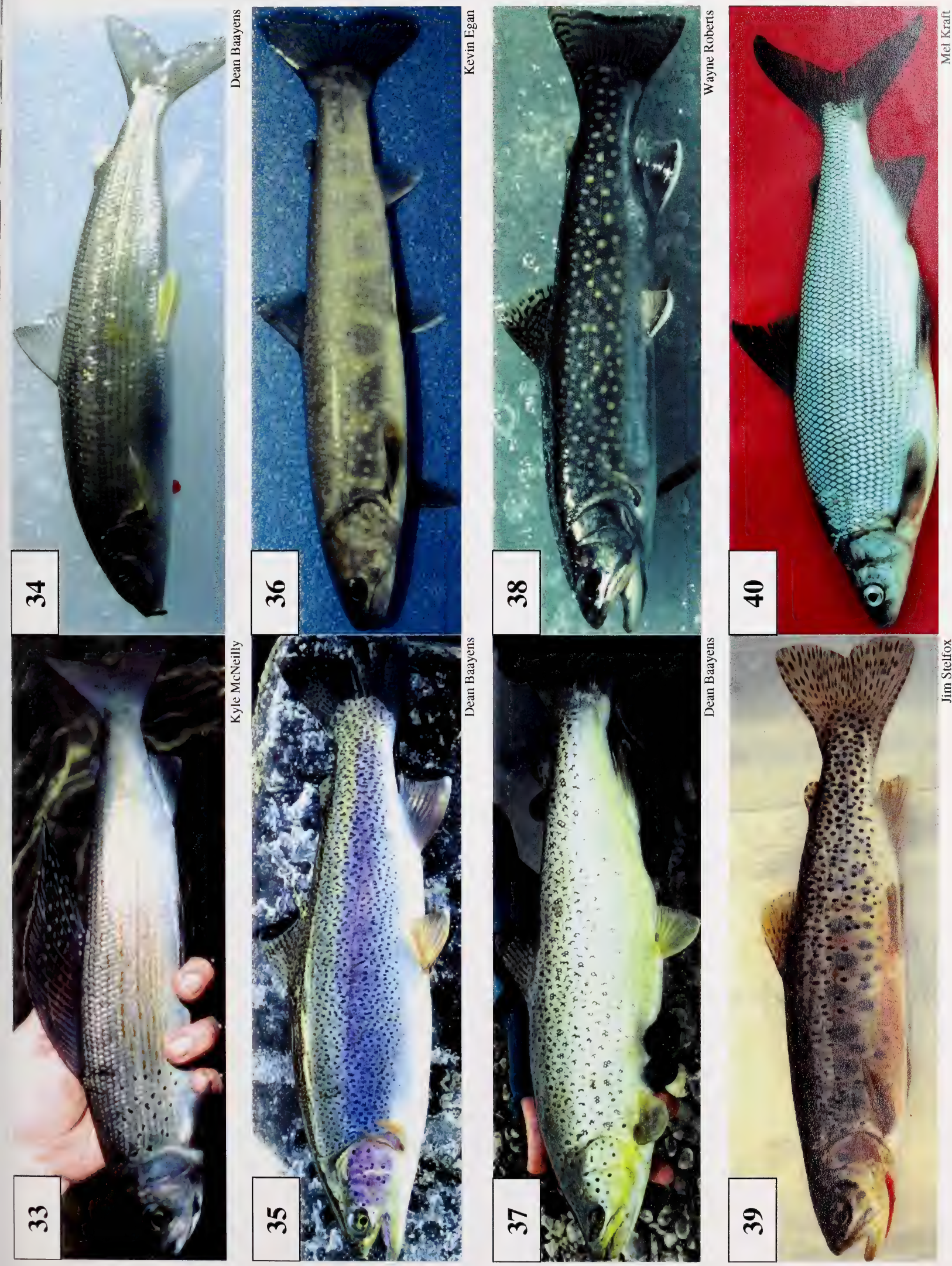

Appendix 2. Objectives and course outline for the salmonid identification course. 



\section{Salmonid Identification Course}

\section{Course Objectives}

The intent is to develop educational material for the identification of salmonids and not to rate an individual's performance. At the outset, the primary objectives are:

1) Develop and assess educational material for the identification of salmonids,

2) Develop and assess a valid testing mechanism to determine participant skill levels in identifying salmonids, and

3) Evaluate the effectiveness of the course as a teaching tool.

Ultimately, Alberta's Salmonid Identification Course is being developed for Alberta Environment, Natural Resources Service to provide educational material for staff to enable them to:

1) Perform their jobs more effectively, and

2) Provide the public with awareness on how to tell apart some of Alberta's sport fish.

Initially, emphasis will be on the sport fish species most commonly found in the streams of the Eastern Slopes; however, future addition of all sport fish species is planned. Staff from a range of job classifications and experience will be encouraged to participate to provide a better evaluation of the effectiveness of the course as a teaching tool. During the course, participants will be informed of their personal results and encouraged to address any problems they encountered. The results of individual tests will remain confidential. It is important to establish a high degree of confidence in the quality of the educational material, to have a high degree of confidence in the course for staff training and for public education.

\section{Course Outline}

Several distinguishing features of sport fish can be used to tell apart the various species; however, some practice is required in the use of these features to separate closely related members, such as salmonid species. The technique used is referred to as "eyeballing fish"-species identification at a glance based on simple criteria such as body form, body structures and markings. Anglers will find the "eyeballing technique" works easiest for identifying fish families and sport fish species. For identification of non-sport fish species and uncommon sport fish species, the detailed keys given in the book "The Fishes of Alberta" (Nelson and Paetz 1992) are recommended.

1. At the start of the course, participants are asked to complete the five-page photo test, without assistance, to establish individual skill levels in salmonid identification based on personal knowledge and experience. This will set individual baselines and enable the evaluation of the quality of the training material and effectiveness of the course as a teaching tool.

2. Participants are now provided the course material (dichotomous key and example pictures). This is the training session of the course and detailed discussions on the techniques of salmonid identification are encouraged. The five-page photo test must be turned over and not viewed during the training session. 
3. When the participants feel comfortable that they have completely reviewed the key, and with the key still in front of them for their use, each is given a clean test sheet so they can do the photo test a second time. The two pages of fish example pictures must be turned over and not viewed during the test. Again, participants should do the test separately and not discuss their answers. This is required to help assess the quality of the test photos and instruction material. While the test is being done the second time, it should be possible for the instructor to grade the first test.

4. The second set of tests is then graded and a summary session is held to discuss the course and material (and individual results, at the request of a participant).

5. When the summary session is completed, all test sheets are collected and placed into an envelope marked "Personal and Confidential." Send the envelope by courier to Fisheries and Wildlife Management Division, Headquarters, attention Dave Berry, Provincial Recreational Fisheries Specialist.

6. The data will be summarized to evaluate the effectiveness of the course as a teaching tool and to determine if any material, particularly individual fish photos, is of questionable quality leading to frequently wrong answers.

\section{NOTES TO PARTICIPANTS:}

1. The salmonid identification key is laid out in a step-by-step sequence to lead you through the process of recognizing the identifying features to separate fish species. Follow the sequence from start to finish each time you identify a fish photo. Don't skip steps, because you are more likely to make errors. In time, you will be able to train yourself to see all the features rapidly in one glance, almost without realizing it.

2. There is no intent to use photos that are difficult or tricky to identify. An effective course should permit every participant the opportunity to correctly identify every photo after receiving the course material and instruction. After establishing confidence in the material and techniques, in the future, an individual's difficulty in fish identification can not be blamed on faulty photos or key-identifying features.

3. At the end of each training session, the test photos, example pictures and key must be returned. These materials are required for future use. Participants should not make any notes or marks on the key or the photos. The salmonid identification material and the course must be fully tested and approved before material can be provided for distribution and public education. This is required to avoid confusion, should changes to photos or other materials are required based on the analysis of the results of the testing process. 
Appendix 3. Test answer sheet for the salmonid identification course. 



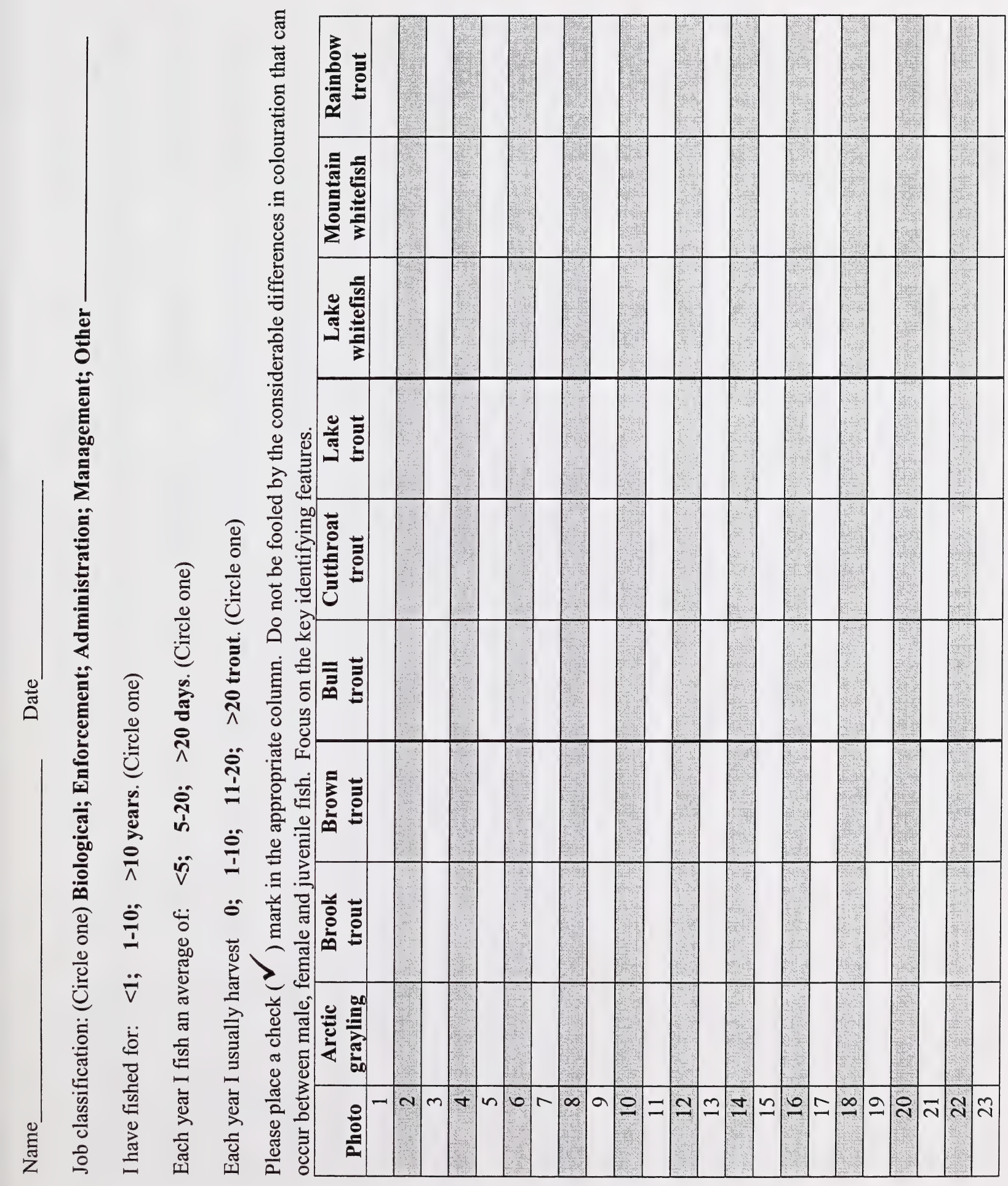




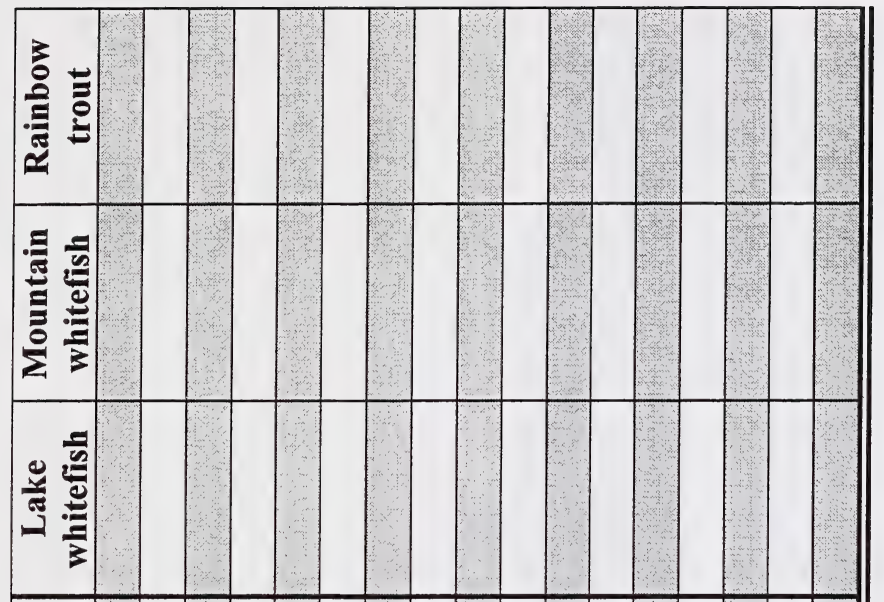

善言

衰言

言言

龉言

\section{亳言}

善亳

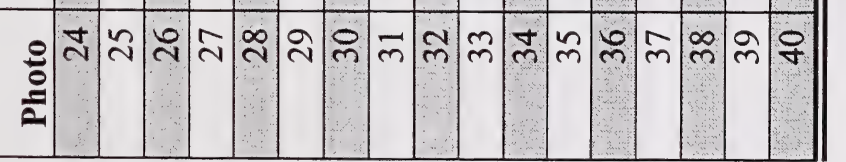

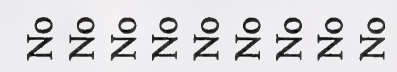

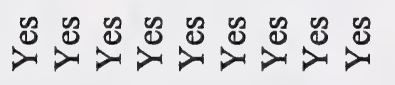

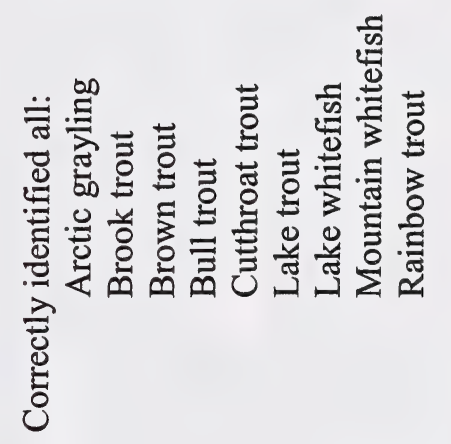

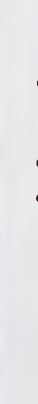





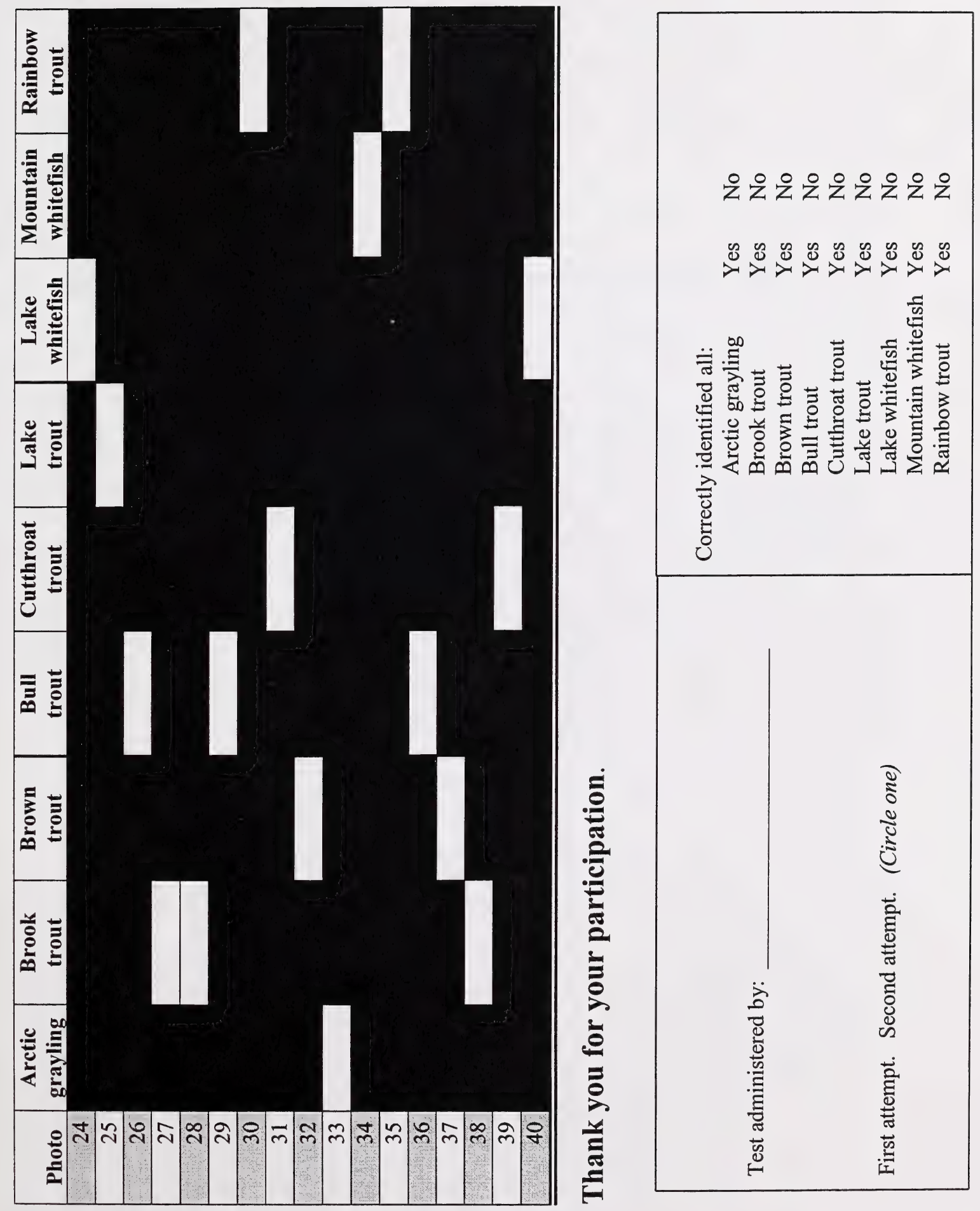

Appendix 4. Detailed discussion of test results for each photo in the salmonid identification test. 

Detailed discussion of test results for each photo in the salmonid identification test. The following is a detailed review of the results for each photo, presented in the order that the photo appeared in the test. To put things in perspective, average first- and second-attempt scores were $69 \%$ and $92 \%$, respectively.

Photo \# Comments

1. This "classic" rainbow trout photo was the most readily identified photo in the test, being correctly identified $93 \%$ and $97 \%$ of the time on the first attempt and second attempts, respectively.

2. Only $60 \%$ correctly identified this brown trout on their first attempt-most frequently misidentifying it as a brook trout-but $95 \%$ correctly identified it on their second attempt.

3. This lake trout was correctly identified only $65 \%$ of the time on the first attempt, but $97 \%$ of the time on the second attempt.

4. Scores for this bull trout were about average on both attempts. Surprisingly, $38 \%$ of the people who incorrectly identified it on their second attempt called it a mountain whitefish, which suggests that they skipped the first step in the key-small versus large scales.

5. Scores for this lake whitefish were above average on both attempts. Although it was only misidentified $4 \%$ of the time on the second attempt, most of those who misidentified it called it a mountain whitefish.

6. Scores were slightly below average for this brown trout on both attempts. The fact that $38 \%$ of the people who incorrectly identified it on their second attempt called it a brook trout suggests that they skipped the second step in the key, since black spots are clearly visible on the side of the fish.

7. This male brook trout, with its brilliant spawning colouration, was correctly identified only $86 \%$ of the time on the second attempt. Of the people who incorrectly identified it on their second attempt, $83 \%$ called it a lake trout, even though the black markings on the dorsal fin are quite prominent.

8. Scores were above average for this cutthroat trout on both attempts. Although only $4 \%$ misidentified the photo on their second attempt, $60 \%$ of these people called it a brook trout. This indicates that they skipped or disregarded the second step in the key, since black spots are clearly visible on the side of the fish. It also suggests that they may have keyed in on the orange colour on the belly-a common feature of brook trout, but not a key-identifying feature. 
9. Only $60 \%$ correctly identified this dark juvenile bull trout on their first attempt-most frequently misidentifying it as a brook trout or lake trout-but $92 \%$ correctly identified it on their second attempt.

10. This pale juvenile brook trout was correctly identified only $58 \%$ of the time on the first attempt, but $92 \%$ of the time on the second attempt. Most (67\%) of the people who misidentified it on their second attempt called it a brown trout, which suggests that they skipped the second step in the key, since there are clearly no black spots on the side of the fish. It is also possible that some of these people jumped to a false conclusion because the reddish spots on the side of the fish inadvertently fooled them into thinking it was a brown trout. Reddish spots are common to both brook and brown trout, but were only mentioned in the key as a secondary-identifying feature for brown trout.

11. This brook trout was most frequently misidentified as a brown trout on the first attempt, likely because of the reddish spots on the sides of the fish. On the second attempt, it was most frequently misidentified as a lake trout, even though the black markings on the dorsal fin are clearly visible.

12. Scores were well below average for this juvenile rainbow trout on both attempts. Of the $22 \%$ who misidentified it on their second attempt, $52 \%$ called it a brown trout and $31 \%$ called it a brook trout. Those who called it a brown trout may have thought that the pale background around the parr marks were pale haloes around black spots. Those who misidentified it as a brook trout likely skipped or disregarded the second step in the key, since black spots are clearly visible on the side of the fish. Instead, they may have focused on the white leading edges on the pelvic and anal fins-a common feature of all char, but not a key-identifying feature.

13. This juvenile brown trout was correctly identified only $54 \%$ of the time on the first attempt, but $92 \%$ of the time on the second attempt. Half of the people who incorrectly identified it on their second attempt called it a brook trout, which suggests that they skipped or disregarded the second step in the key, since black spots are clearly visible on the side of the fish. The white leading edges on the pelvic and anal fins-a common feature of all char, but not a key-identifying feature-may have been a factor in this brown trout being misidentified as a brook trout.

14. Of all the cutthroat trout photos in the test, this one was the most frequently misidentified. Of the $11 \%$ who misidentified it on their second attempt, $83 \%$ called it a rainbow trout. This may have been because the red-orange slash under the jaw is not as bright as in the other cutthroat trout photos, or because the spotting pattern on the sides is more typical of that seen on rainbow trout.

15. Scores for this female Arctic grayling were well above average on both attempts, with $97 \%$ correctly identifying it on the second attempt. Those who misidentified it usually called it a mountain whitefish. 
16. Scores for this mountain whitefish were above average on the first attempt and well above average on the second attempt. In both cases, those who misidentified it usually called it a lake whitefish. Surprisingly, $38 \%$ of the people who misidentified it on their second attempt called it a bull trout, which suggests that they skipped the first step in the key-small versus large scales.

17. Scores for this brown trout were above average on both attempts. Most (62\%) of the people who incorrectly identified it on their second attempt called it a brook trout, which suggests that they skipped the second step in the key, since black spots are clearly visible on the side of the fish.

18. Scores were below average for this lake trout on both attempts. Of the $11 \%$ who misidentified it on their second attempt, most called it a brook trout or bull trout, perhaps due to the poor orientation of the dorsal fin and faint markings on the dorsal fin.

19. Scores for this "classic" rainbow trout photo were well above average on both attempts, with $98 \%$ correctly identifying it on their second attempt.

20. Although scores for this juvenile bull trout were below average on the first attempt, scores were above average ( $96 \%)$ on the second attempt.

21. Scores for this dark brook trout were above average on both attempts. Although only $3 \%$ misidentified it on their second attempt, most of those who did called it a brown trout, suggesting that they skipped the second step in the key.

22. Scores for this brilliantly coloured male Arctic grayling were well above average on both attempts.

23. This native Athabascan rainbow trout was the least frequently identified photo in the test, with a score of only $71 \%$ on the second attempt. Of those who misidentified it on their second attempt, $45 \%$ called it a brown trout and $41 \%$ called it a brook trout. Those who called it a brown trout may have thought that the pale backgrounds around the parr marks were pale haloes around black spots. Those who misidentified it as a brook trout likely skipped or disregarded the second step in the key, since black spots are clearly visible on the side of the fish.

24. Scores for this lake whitefish were above average on both attempts. Of the $3 \%$ who misidentified it on their second attempt, $88 \%$ called it a mountain whitefish.

25. This lake trout was correctly identified only $58 \%$ of the time on the first attempt, but $95 \%$ of the time on the second attempt. Of those who misidentified it on the first attempt, most called it a brown trout or bull trout. Of the $5 \%$ who misidentified it on the second attempt, $46 \%$ called it a brook trout, perhaps because the dark background made it appear as if there were black markings on the dorsal fin. 
26. This large, adult bull trout was the most readily identified bull trout in the test. Of the $30 \%$ who misidentified it on their first attempt and $4 \%$ who misidentified it on their second attempt, almost half called it a lake trout.

27. This female brook trout was correctly identified only $80 \%$ of the time on the second attempt. Of the people who misidentified it on their second attempt, $62 \%$ called it a lake trout, which suggests that they had difficulty determining whether the dorsal fin had black markings on a pale background or pale spots on a dark background.

28. Scores for this brilliantly coloured male brook trout were well above average on both attempts. Of the $5 \%$ who misidentified it on their second attempt, $50 \%$ called it a brown trout, suggesting that they skipped the second step in the key.

29. This large, female bull trout was the least readily identified bull trout in the test, with only $53 \%$ correctly identifying it on their first attempt and $84 \%$ correctly identifying it on their second attempt. Of those who misidentified it on their second attempt, $44 \%$ called it a cutthroat, rainbow or brown trout. This suggests that they skipped the second step in the key, since there are clearly no black spots on the side of the fish.

30. Scores for this silvery rainbow trout were below average on both attempts. Of the $16 \%$ who misidentified it on their second attempt, $64 \%$ called it a mountain whitefish, lake whitefish or Arctic grayling. This suggests that some people had a hard time differentiating between the relatively prominent scales on the fish in this photo and the much larger scales of whitefish and grayling.

31. Scores for this cutthroat trout were above average on both attempts. Although only $4 \%$ misidentified the photo on their second attempt, $45 \%$ of these people called it a brook trout. These people likely skipped or disregarded the second step in the key, since black spots are clearly visible on the side of the fish.

32. This large female brown trout was correctly identified only $52 \%$ of the time on the first attempt, but $90 \%$ of the time on the second attempt. Most (70\%) of the people who misidentified it on their second attempt called it a rainbow trout, which suggests that they either overlooked or had difficulty seeing the pale haloes around the black spots.

33. Scores for this male Arctic grayling were well above average on both attempts. The score of $99 \%$ on the second attempt was the highest score for any fish in the test.

34. Scores for this mountain whitefish were above average on the first attempt and well above average on the second attempt. In both cases, people who misidentified it usually called it a lake whitefish. Surprisingly, $22 \%$ of those who misidentified it on their second attempt called it a bull trout, which suggests that they skipped the first step in the key-small versus large scales. 
35. Scores for this "classic" rainbow trout photo were well above average on both attempts, with $90 \%$ correctly identifying it on their first attempt. Of the $5 \%$ who misidentified it on their second attempt, $69 \%$ called it a brown trout. It is likely that these people keyed in on the above-average number of black spots on the gill cover, since there are no pale haloes around the black spots.

36. Only $62 \%$ correctly identified this juvenile bull trout on their first attempt, most frequently misidentifying it as a brown trout or brook trout. Of the $8 \%$ who misidentified it on their second attempt, $50 \%$ called it a lake trout.

37. Scores for this brown trout were below average on both attempts. Most (74\%) of the people who misidentified it on their second attempt called it a rainbow trout, which suggests that they either overlooked or had difficulty seeing the pale haloes around the black spots.

38. Scores for this dark brook trout were about average on both attempts. Of the people who misidentified it on their second attempt, $81 \%$ called it a lake trout, which suggests that they had difficulty determining whether it had black markings on a pale background or pale spots on a dark background.

39. Scores for this cutthroat trout were well above average on both attempts. Although only $3 \%$ misidentified it on their second attempt, $50 \%$ of these people called it a brook trout. This indicates that they skipped or disregarded the second step in the key, since black spots are clearly visible on the side of the fish. It also suggests that they may have keyed in on the orange colour on the belly-a common feature of brook trout, but not a key-identifying feature.

40. Scores for this lake whitefish were above average on the first attempt but below average on the second attempt. Of the $14 \%$ who misidentified it on their second attempt, $89 \%$ called it a mountain whitefish. The relatively low score on the second attempt is likely due to the position of the dorsal fin, which is more erect than in the other lake whitefish photos (5 and 24). This would make it harder to determine whether the dorsal fin is higher than long (i.e., the anterior ray extends beyond the posterior ray when the fin is flattened). 


National Library of Canada
Bibliothèque nationale du Canada

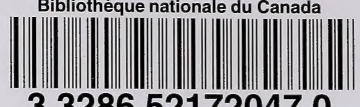
3 3286521720470 